\title{
Common fixed point for fuzzy mappings satisfying an implicit $\varphi$-contractive conditions in complete metric spaces
}

\author{
Ming-Liang Song \\ Mathematics and Information Technology School, Jiangsu Second Normal University, Nanjing, 210013, P. R. China. \\ Communicated by C. Alaca
}

\begin{abstract}
In this paper, by using $\mathscr{F} \varphi$-type real functions, some common fixed point for fuzzy mappings satisfying an implicit $\varphi$ contractive conditions in complete metric spaces are established. Our results extend, generalize, and improve some existing results. Moreover, some applications and two examples are given here to illustrate the validity of the hypotheses of our main results. (C)2017 All rights reserved.
\end{abstract}

Keywords: Common fixed point, fuzzy mapping, implicit $\varphi$-contractive condition, multi-valued mappings, complete metric space.

2010 MSC: 47H10, 54H25, 54A40, 46A40.

\section{Introduction and preliminaries}

Fixed point theorems and their applications for fuzzy contraction mappings in a metric linear space were first studied in 1981 by Heilpern [8]. In recent years, some authors have obtained fixed point results for various classes of fuzzy contraction mappings in a metric space and a metric linear space (for examples, see $[1-7,10,12-15,17,18])$.

Recently, Beg and Ahmed [5] proved two common fixed point theorems for fuzzy mappings satisfying an implicit relation in complete metric spaces. On the other hand, Chen and Huang [6] proved some fixed point theorems for fuzzy mappings under a G-distance function and a $\mathrm{G}^{\prime}$-distance function in complete metric spaces. These theorems extended the known contractive-type conditions.

Inspired by the work of $[5,6]$, in this paper we discuss the existence of common fixed point for fuzzy mappings satisfying an implicit $\varphi$-contractive conditions in complete metric spaces. In Sections 2 and 3 , we first introduce the new real function class $\mathscr{F}_{\varphi}$ satisfying an implicit $\varphi$-contractive conditions. Then, by using $\mathscr{F}_{\varphi}$-type real functions, some common fixed point theorems for fuzzy mappings satisfying an implicit $\varphi$-contractive conditions in complete metric spaces are established. Our main results extend, generalize and improve the results of $[1-8,13,14]$. In Section 4 , as applications, we obtain the corresponding common fixed point theorems for multi-valued mappings in complete metric spaces. Also, two examples, which show the validity of the hypotheses of our main results, are given.

Email address: mlsong2004@163.com (Ming-Liang Song)

doi:10.22436/jnsa.010.06.43 
Throughout this paper we shall use the following notations and lemmas which have been recorded from $[5,6,8,10,11]$.

Let $X$ and $Y$ be nonempty sets. A multi-valued mapping $T$ from $X$ to $Y$, denoted by $T: X \rightarrow 2^{Y}$, is defined to be a function that assigns to each element of $X$, a nonempty subset of $Y$. Fixed points of the multi-valued mapping $T: X \rightarrow 2^{X}$ will be the points $x \in X$ such that $x \in T(x)$.

Let $(\mathrm{X}, \mathrm{d})$ be a metric space. Let $\mathscr{C} \mathscr{B}(\mathrm{X})$ denote the set of all nonempty closed and bounded subsets of $\mathrm{X}$, and $\mathscr{C}(\mathrm{X})$ denote the set of all nonempty compact subsets of $\mathrm{X}$. For $\mathrm{A}, \mathrm{B} \in \mathscr{C} \mathscr{B}(\mathrm{X})$ define

$$
H(A, B)=\max \left\{\sup _{x \in A} d(x, B), \sup _{y \in B} d(A, y)\right\},
$$

where $d(x, A)=\inf _{y \in A} d(x, y)$.

A fuzzy set in $X$ is a function with domain $X$ and values in $[0,1]$. If $A$ is a fuzzy set and $x \in X$, then the function values $A(x)$ is called the grade of membership of $x$ in $A$. The $\alpha$-level set of $A$ is denoted by $[A]_{\alpha}$, and is defined as follows:

$$
[A]_{\alpha}=\{x: A(x) \geqslant \alpha\} \text { if } \alpha \in(0,1], \quad[A]_{0}=\overline{\{x: A(x)>0\}} .
$$

Here, $\bar{B}$ denotes the closure of the set $B$. Let $\mathscr{F}(X)$ be the collection of all fuzzy sets in a metric space $X$. For $A, B \in \mathscr{F}(X), A \subset B$ means $A(x) \leqslant B(x)$ for each $x \in X$.

A mapping $T$ from $X$ to $\mathscr{F}(Y)$ is called a fuzzy mapping if for each $x \in X, T(x)$ (sometimes denoted by $T x$ ) is a fuzzy set on $Y$ and $T x(y)$ denotes the degree of membership of $y$ in $T x$. A fuzzy point $x_{\alpha}$ in $X$ is called a fixed fuzzy point of the fuzzy mapping $T$ if $x_{\alpha} \subset T x$. If $\{x\} \subset T x$, then $x$ is a fixed point of $T$.

Let $\mathscr{W}_{\alpha}(\mathrm{X})$ denote the set of all fuzzy sets on $\mathrm{X}$ such that each of its $\alpha$-level is a nonempty compact subset of $X$. For $x \in X, A, B \in \mathscr{W}_{\alpha}(X)$ define

$$
D(A, B)=\sup _{\alpha \in(0,1]} H\left(A_{\alpha}, B_{\alpha}\right), \quad d(x, A)=\sup _{\alpha \in(0,1]} d\left(x, A_{\alpha}\right) .
$$

Lemma 1.1 (Nadler [11]). Let $(\mathrm{X}, \mathrm{d})$ be a metric space and $\mathrm{A}, \mathrm{B} \in \mathscr{C}(\mathrm{X})$, then

(1) for each $x \in A, d(x, B) \leqslant H(A, B)$;

(2) for each $y \in X, d(x, A) \leqslant d(x, y)+d(y, A)$.

Lemma 1.2 (Nadler [11]). Let $(\mathrm{X}, \mathrm{d})$ be a metric space and $\mathrm{A}, \mathrm{B} \in \mathscr{C}(\mathrm{X})$, then for each $\mathrm{x} \in \mathrm{A}$, there exists an element $\mathrm{y} \in \mathrm{B}$ such that $\mathrm{d}(\mathrm{x}, \mathrm{y}) \leqslant \mathrm{H}(\mathrm{A}, \mathrm{B})$.

Lemma 1.3 (Heilpern [8]). Let $x \in X$ and $A \in \mathscr{W}_{\alpha}(X)$. Then $x_{\alpha} \subset A$ if $d\left(x, A_{\alpha}\right)=0$ for all $\alpha \in[0,1]$.

Lemma 1.4 (Lee and Cho [10]). Let $(\mathrm{X}, \mathrm{d})$ be a metric space and $\mathrm{T}$ be a fuzzy mapping from $\mathrm{X}$ into $\mathscr{W}_{\alpha}(\mathrm{X})$ with $\mathrm{x}_{0} \in \mathrm{X}$. Then there exists $\mathrm{x}_{1} \in \mathrm{X}$ such that $\left\{\mathrm{x}_{1}\right\} \subset \mathrm{T} \mathrm{x}_{0}$.

\section{The real functions satisfying an implicit $\varphi$-contractive conditions}

Definition 2.1. Let $\varphi: \mathbb{R}^{+}=[0,+\infty) \rightarrow \mathbb{R}^{+}$be a function and $\varphi^{\mathfrak{n}}(\mathrm{t})$ denote the $\mathrm{nth}$ iteration of $\varphi(t)$.

(1) $\varphi$ is said to satisfy the condition $(\Phi)$ if it is nondecreasing, and there exists a constant $M>0$ such that $\varphi(t)<$ Mt for all $t>0$.

(2) $\varphi$ is said to satisfy the condition $\left(\Phi_{0}\right)$ if it is nondecreasing, lower semi-continuous, and $\sum_{n=0}^{\infty} \varphi^{n}(t)<$ $+\infty$ for all $t>0$.

Remark 2.2. Obviously, if $\varphi(t)$ satisfies the condition $\left(\Phi_{0}\right)$, then $\varphi(t)<t$ for all $t>0$, i.e., $\left(\Phi_{0}\right) \subset(\Phi)$. Since $\varphi(t)=\frac{t}{1+t}$ satisfies the condition $(\Phi)$ and does not satisfy the condition $\left(\Phi_{0}\right),\left(\Phi_{0}\right)$ does not imply $(\Phi)$, i.e., $(\Phi) \not \subset\left(\Phi_{0}\right)$. Also, if $\varphi(\mathrm{t})$ satisfies the condition $(\Phi)$, then $\varphi(0)=0$. 
Definition 2.3. A function $F: \mathbb{R}_{6}^{+} \rightarrow \mathbb{R}=(-\infty,+\infty)$ is called a real function satisfying an implicit $\varphi$-contractive condition, if the following conditions are satisfied:

$(\mathscr{F}-1) \mathrm{F}$ is lower semi-continuous;

$(\mathscr{F}-2) \mathrm{F}$ is nondecreasing in 1st coordinate variable and nonincreasing in 3rd, 4th, 5th, 6th coordinate variable;

( $\mathscr{F}$-3) there exist $\varphi_{1}, \varphi_{2} \in(\Phi)$ with $\varphi=\varphi_{2} \circ \varphi_{1} \in\left(\Phi_{0}\right)$ such that for all $u, v \geqslant 0$, we have

$(\mathscr{F}-3 a) u \leqslant \varphi_{1}(v)$, whenever $\mathrm{F}(\mathrm{u}, v, v, u, u+v, 0) \leqslant 0$;

$(\mathscr{F}-3 b) u \leqslant \varphi_{2}(v)$, whenever $F(u, v, u, v, 0, u+v) \leqslant 0$.

We denote by $\mathscr{F}_{\varphi}$ the collection of all real functions $F: \mathbb{R}_{6}^{+} \rightarrow \mathbb{R}$ satisfying an implicit $\varphi$-contractive conditions.

The following examples show that the $\mathscr{F}_{\varphi}$ is a largish class of real functions.

Example 2.4. Let the function $F_{1}: \mathbb{R}_{6}^{+} \rightarrow \mathbb{R}$ as follows:

$$
F_{1}\left(t_{1}, t_{2}, t_{3}, t_{4}, t_{5}, t_{6}\right)=t_{1}-\phi\left(\max \left\{t_{2}, t_{3}, t_{4}, t_{5}, t_{6}\right\}\right) t_{2},
$$

where $\phi:[0,+\infty) \rightarrow[0,1)$, and $\phi$ is nondecreasing and lower semi-continuous. Then $\mathrm{F}_{1} \in \mathscr{F}_{\varphi}$.

In fact, it is evident that $\mathrm{F}_{1}$ satisfies conditions $(\mathscr{F}-1)$ and $(\mathscr{F}-2)$ of Definition 2.3. If $\mathrm{F}_{1}(\mathrm{u}, v, v, u, u+$ $v, 0) \leqslant 0$ or $\mathrm{F}_{1}(\mathrm{u}, v, u, v, 0, u+v) \leqslant 0$ with $v>0$, then we have $u \leqslant \phi(u+v) v<v$. This implies $u \leqslant$ $\phi(2 v) v$. Let $\varphi_{1}(\mathrm{t})=\varphi_{2}(\mathrm{t})=\phi(2 \mathrm{t}) \mathrm{t}$. Note that $\phi$ is nondecreasing, then we have $\varphi(t)=\varphi_{2}\left(\varphi_{1}(\mathrm{t})\right)=$ $\phi(2 \phi(2 t) t) \phi(2 t) t \leqslant \phi^{2}(2 t) t$. It follows by induction that $\varphi^{n}(t) \leqslant \phi^{2 n}(2 t) t$. Since $\phi(2 t)<1$, we have $\sum_{n=0}^{\infty} \varphi^{n}(t)<+\infty$, i.e., $\varphi(t) \in\left(\Phi_{0}\right)$. In addition, if $v=0$, then $u=0 \leqslant \varphi(v)=\varphi(0)=0$. This shows that $\mathrm{F}_{1}$ satisfies condition $(\mathscr{F}-3)$ of Definition 2.3. Hence $\mathrm{F}_{1} \in \mathscr{F}_{\varphi}$.

Example 2.5. Let $a, b, c, d \geqslant 0$ with $a+b+c<1$. We define the functions $F_{2}, F_{3}: \mathbb{R}_{6}^{+} \rightarrow \mathbb{R}$ by

$$
\begin{aligned}
& F_{2}\left(t_{1}, t_{2}, t_{3}, t_{4}, t_{5}, t_{6}\right)=t_{1}-a t_{2}-b t_{3}-c t_{4}-d \sqrt{t_{5} t_{6}} \\
& F_{3}\left(t_{1}, t_{2}, t_{3}, t_{4}, t_{5}, t_{6}\right)=t_{1}-\frac{\left(a t_{2}+b t_{3}+c t_{4}\right) t_{2}}{1+t_{1}+t_{2}}-d t_{5} t_{6} .
\end{aligned}
$$

It is easy to see that $\mathrm{F}_{2}, \mathrm{~F}_{3} \in \mathscr{F}_{\varphi}$.

Example 2.6. Let $\phi \in\left(\Phi_{0}\right)$. The function $\mathrm{F}_{4}: \mathbb{R}_{6}^{+} \rightarrow \mathbb{R}$ is defined by

$$
F_{4}\left(t_{1}, t_{2}, t_{3}, t_{4}, t_{5}, t_{6}\right)=\left(1+t_{2}\right) t_{1}-\phi\left(\max \left\{t_{3} t_{4}, t_{5} t_{6}\right\}\right)-\phi\left(\max \left\{t_{2}, t_{3}, t_{4}\right\}\right),
$$

then $\mathrm{F}_{4} \in \mathscr{F}_{\varphi}$.

In fact, it is evident that $\mathrm{F}_{4}$ satisfies conditions $(\mathscr{F}-1)$ and $(\mathscr{F}-2)$ of Definition 2.3. Now suppose that $\mathrm{F}_{4}(u, v, v, u, u+v, 0) \leqslant 0$ or $\mathrm{F}_{4}(u, v, u, v, 0, u+v) \leqslant 0$. If $u=0$, then $u \leqslant \phi(v)$ holds evidently. If $u>0$, then we have $(1+v) u \leqslant \phi(u v)+\phi(\max \{u, v\})<u v+\max \{u, v\}$, which implies that $u<\max \{u, v\}$, and so $u<v$. Hence, we have $(1+v) u \leqslant \phi(u v)+\phi(v)$ which implies $u<\phi(v)$. Let $\varphi_{1}(t)=\varphi_{2}(t)=\phi(t)$. Note that $\phi \in\left(\Phi_{0}\right)$, we have $\varphi(t) \in\left(\Phi_{0}\right)$. Therefore $F_{4} \in \mathscr{F}_{\varphi}$.

Example 2.7. Let $p>0, a, b, c, d \geqslant 0$ with $a+b+c<1$. The function $F_{5}: \mathbb{R}_{6}^{+} \rightarrow \mathbb{R}$ is defined by

$$
F_{5}\left(t_{1}, t_{2}, t_{3}, t_{4}, t_{5}, t_{6}\right)=t_{1}-\left(a t_{2}^{p}+b t_{3}^{p}+c t_{4}^{p}\right)^{\frac{1}{p}}-d t_{5} t_{6},
$$

then $\mathrm{F}_{5} \in \mathscr{F}_{\varphi}$.

In fact, it is evident that $\mathrm{F}_{5}$ satisfies conditions $(\mathscr{F}-1)$ and $(\mathscr{F}-2)$ of Definition 2.3. If $\mathrm{F}_{5}(\mathrm{u}, v, v, u, u+$ $v, 0) \leqslant 0$, i.e., $u \leqslant\left(a v^{p}+b v^{p}+c u^{p}\right)^{\frac{1}{p}}$, then we have $(1-c) u^{p} \leqslant(a+b) v^{p} \leqslant(1-c) v^{p}$, i.e., $u \leqslant v$. Thus, $u \leqslant\left(a v^{p}+b v^{p}+c v^{p}\right)^{\frac{1}{p}}=(a+b+c)^{\frac{1}{p}} v=\varphi_{1}(v)$.

Similarly, we can prove that $F_{5}(u, v, u, v, 0, u+v) \leqslant 0$ implies that $u \leqslant(a+b+c)^{\frac{1}{p}} v=\varphi_{2}(v)$. Note that $\varphi_{1}(\mathrm{t})=\varphi_{2}(\mathrm{t}) \in\left(\Phi_{0}\right)$, we have $\varphi(t) \in\left(\Phi_{0}\right)$. Therefore $F_{5} \in \mathscr{F}_{\varphi}$. 
Example 2.8. Let $\phi_{1}, \cdots, \phi_{5}: \mathbb{R}^{+} \rightarrow[0,1)$ be five continuous functions, and there exist $a>0, b>0, C>$ $0, \mathrm{D}>0$ with $\mathrm{CD}<\mathrm{ab}$, such that

$$
\begin{aligned}
& \inf _{t \geqslant 0}\left\{1-\phi_{2}(t)-\phi_{5}(t)\right\}=a, \\
& \sup _{t \geqslant 0}\left\{\phi_{1}(t)+\phi_{2}(t)+\phi_{4}(t)\right\}=C \text {, } \\
& \inf _{\mathrm{t} \geqslant 0}\left\{1-\phi_{3}(\mathrm{t})-\phi_{4}(\mathrm{t})\right\}=\mathrm{b}, \\
& \sup _{t \geqslant 0}\left\{\phi_{1}(t)+\phi_{3}(t)+\phi_{5}(t)\right\}=D \text {. }
\end{aligned}
$$

We define the function $\mathrm{F}_{6}: \mathbb{R}_{6}^{+} \rightarrow \mathbb{R}$ as follows:

$$
F_{6}\left(t_{1}, t_{2}, t_{3}, t_{4}, t_{5}, t_{6}\right)=t_{1}-\left(\phi_{1}\left(t_{2}\right) t_{2}+\phi_{2}\left(t_{2}\right) t_{3}+\phi_{3}\left(t_{2}\right) t_{4}+\phi_{4}\left(t_{2}\right) t_{5}+\phi_{5}\left(t_{2}\right) t_{6}\right) .
$$

Then $\mathrm{F}_{6} \in \mathscr{F}_{\varphi}$.

In fact, it is easy to see that the conditions $(\mathscr{F}-1)$ and $(\mathscr{F}-2)$ of Definition 2.3 are satisfied. For any $u, v \geqslant 0$, if $\mathrm{F}_{6}(\mathrm{u}, v, v, u, v+u, 0) \leqslant 0$, then we have $u-\left(\phi_{1}(v) v+\phi_{2}(v) v+\phi_{3}(v) u+\phi_{4}(v)(v+u)\right) \leqslant 0$, which implies that $u \leqslant \frac{\phi_{1}(v)+\phi_{2}(v)+\phi_{4}(v)}{1-\phi_{3}(v)-\phi_{4}(v)} v$ and it yields $u \leqslant \frac{c}{b} v$. Similarly, if $F_{6}(u, v, u, v, 0, v+u) \leqslant 0$, then we have $u \leqslant \frac{\phi_{1}(v)+\phi_{3}(v)+\phi_{5}(v)}{1-\phi_{2}(v)-\phi_{5}(v)} v \leqslant \frac{D}{a} v$. Let $\varphi_{1}(t)=\frac{C}{b} t, \varphi_{2}(t)=\frac{D}{a} t$. Note that $C D<a b$, we have $\varphi(\mathrm{t})=\frac{\mathrm{CD}}{\mathrm{ab}} \mathrm{t} \in\left(\Phi_{0}\right)$ and $\varphi_{1}, \varphi_{2} \in(\Phi)$, i.e., $(\mathscr{F}-3)$ holds. Hence $\mathrm{F}_{6} \in \mathscr{F}_{\varphi}$.

Example 2.9. Let the function $F_{7}: \mathbb{R}_{6}^{+} \rightarrow \mathbb{R}$ be defined by

$$
F_{7}\left(t_{1}, t_{2}, t_{3}, t_{4}, t_{5}, t_{6}\right)=t_{1}-\left(\frac{t_{2}+1}{20 t_{2}+21} t_{2}+\frac{t_{2}+1}{20 t_{2}+21} t_{3}+\frac{2 t_{2}+1}{5 t_{2}+6} t_{4}+\frac{t_{2}+1}{40 t_{2}+42} t_{5}+\frac{t_{2}+1}{2 t_{2}+3} t_{6}\right),
$$

then $\mathrm{F}_{7} \in \mathscr{F}_{\varphi}$.

In fact, in Example 2.8, taking $\phi_{1}(t)=\frac{t+1}{20 t+21}, \phi_{2}(t)=\frac{t+1}{20 t+21}, \phi_{3}(t)=\frac{2 t+1}{5 t+6}, \phi_{4}(t)=\frac{t+1}{40 t+42}, \phi_{5}(t)$ $=\frac{t+1}{2 t+3}$, we obtain five continuous functions $\phi_{1}, \cdots, \phi_{5}$ from $\mathbb{R}^{+}$into $[0,1)$ satisfying the following conditions:

$$
\begin{aligned}
\inf _{t \geqslant 0}\left\{1-\phi_{2}(t)-\phi_{5}(t)\right\} & =\frac{9}{20}, & \inf _{t \geqslant 0}\left\{1-\phi_{3}(t)-\phi_{4}(t)\right\} & =\frac{23}{40}, \\
\sup _{t \geqslant 0}\left\{\phi_{1}(t)+\phi_{2}(t)+\phi_{4}(t)\right\} & =\frac{1}{8}, & \sup _{t \geqslant 0}\left\{\phi_{1}(t)+\phi_{3}(t)+\phi_{5}(t)\right\} & =\frac{19}{20} .
\end{aligned}
$$

It is evident that $\frac{1}{8} \cdot \frac{19}{20}=\frac{19}{160}<\frac{207}{800}=\frac{9}{20} \cdot \frac{23}{40}$, and so all conditions of Example 2.8 are satisfied. Therefore, $\mathrm{F}_{7} \in \mathscr{F}_{\varphi}$.

Example 2.10. Let $a, b, c, d, e \in[0,1)$ with $c+d<1$ and $b+e<1$. There exists $\delta>0$ such that $\mathrm{a}+\mathrm{b}+\mathrm{c}+\mathrm{d}+\mathrm{e}=1+\delta$ and $(\mathrm{c}-\mathrm{b})(\mathrm{e}-\mathrm{d})>2 \delta$. We define the function $\mathrm{F}_{8}: \mathbb{R}_{6}^{+} \rightarrow \mathbb{R}$ as follows:

$$
F_{8}\left(t_{1}, t_{2}, t_{3}, t_{4}, t_{5}, t_{6}\right)=t_{1}-\left(a t_{2}+b t_{3}+c t_{4}+d t_{5}+e t_{6}\right),
$$

then $\mathrm{F}_{8} \in \mathscr{F}_{\varphi}$.

Obviously, in Example 2.8, taking $\phi_{1}(\mathrm{t})=\mathrm{a}, \phi_{2}(\mathrm{t})=\mathrm{b}, \phi_{3}(\mathrm{t})=\mathrm{c}, \phi_{4}(\mathrm{t})=\mathrm{d}, \phi_{5}(\mathrm{t})=\mathrm{e}$, we obtain five continuous functions $\phi_{1}, \cdots, \phi_{5}$ from $\mathbb{R}^{+}$into $[0,1)$. Moreover, $0<1-b-e, 0<1-c-d$ is obvious. Note that $a<1$ and $(c-b)(e-d)>2 \delta$, it follows that

$$
a(1+\delta)+b e+c d<a+\delta+b e+c d<a-\delta+b d+c e .
$$

By $a+b+c+d+e=1+\delta$, we obtain

$$
\mathrm{a}(\mathrm{a}+\mathrm{b}+\mathrm{c}+\mathrm{d}+\mathrm{e})+\mathrm{be}+\mathrm{cd}+\mathrm{bc}+\mathrm{de}<1-\mathrm{b}-\mathrm{c}-\mathrm{d}-\mathrm{e}+\mathrm{bd}+\mathrm{ce}+\mathrm{bc}+\mathrm{de},
$$

which implies that $(a+b+d)(a+c+e)<(1-c-d)(1-b-e)$. Hence, the conditions of Example 2.8 are satisfied. Thus, by Example 2.8, we have $\mathrm{F}_{8} \in \mathscr{F}_{\varphi}$. 
Remark 2.11. The numbers $\mathrm{a}, \mathrm{b}, \mathrm{c}, \mathrm{d}, \mathrm{e}$ and $\delta$ in Example 2.10 really exist. For example, if we take $\delta=$ $\frac{1}{40}, a=\frac{1}{20}, b=\frac{1}{20}, c=\frac{2}{5}, d=\frac{1}{40}, e=\frac{1}{2}$, then $a+b+c+d+e=1+\frac{1}{40}, a+d+e=\frac{23}{40}<1, c+d=\frac{17}{40}<$ $1, b+e=\frac{11}{20}<1$, and $(c-b)(e-d)=\frac{133}{800}>\frac{1}{20}$, i.e., the conditions of Example 2.10 are satisfied.

Example 2.12. Define the function $F_{9}: \mathbb{R}_{6}^{+} \rightarrow \mathbb{R}$ as follows:

$$
F_{9}\left(t_{1}, t_{2}, t_{3}, t_{4}, t_{5}, t_{6}\right)=t_{1}-\left(a t_{2}+b t_{3}+c t_{4}+d t_{5}+e t_{6}\right),
$$

where $a, b, c, d, e$ are nonnegative real numbers, with $a+b+c+d+e=1$ and either $c>b, e>d$ or $\mathrm{c}<\mathrm{b}, \mathrm{e}<\mathrm{d}$. Then $\mathrm{F}_{9} \in \mathscr{F}_{\varphi}$.

In fact, we take $\phi_{1}(t)=a, \phi_{2}(t)=b, \phi_{3}(t)=c, \phi_{4}(t)=d, \phi_{5}(t)=e$. If $c>b, e>d$, we have $(a+b+d)(a+c+e)=(1-c-e)(1-b-d)<(1-c-d)(1-b-e)$, i.e., the conditions of Example 2.8 are satisfied. Similarly, we can prove the case of $c<b, e<d$. Therefore, by Example 2.8, we have $\mathrm{F}_{9} \in \mathscr{F}_{\varphi}$.

Definition 2.13 (Beg and Ahmed [5]). A function $F: \mathbb{R}_{6}^{+} \rightarrow \mathbb{R}$ is called a real function satisfying an implicit conditions, if the following conditions are satisfied:

$\left(\psi_{1}\right) \mathrm{F}$ is lower semi-continuous;

$\left(\psi_{2}\right) \mathrm{F}$ is nondecreasing in 1st coordinate variable and nonincreasing in 3rd, 4th, 5th, 6th coordinate variable;

$\left(\psi_{3}\right)$ there exists $h \in(0,1)$ such that for all $u, v \geqslant 0$, we have

$\left(\psi_{31}\right) u \leqslant h v$, whenever $F(u, v, v, u, u+v, 0) \leqslant 0$;

$\left(\psi_{32}\right) u \leqslant h v$, whenever $F(u, v, u, v, 0, u+v) \leqslant 0$;

$\left(\psi_{4}\right)$ for all $u>0$, we have $F(u, u, 0,0, u, u)>0$.

We denote by $\Psi$ the collection of all real functions $\mathrm{F}: \mathbb{R}_{6}^{+} \rightarrow \mathbb{R}$ satisfying the conditions of Definition 2.13.

Remark 2.14. A slight difference between the original definition in [5] and Definition 2.3 is that in Definition 2.3, $\mathrm{F}$ is nondecreasing in 1st coordinate variable. In fact, in Beg and Ahmed [5], the proof of Theorem 2.6 depends strongly on nondecreasing of $F$ in 1st coordinate variable. This shows that nondecreasing of $F$ in 1st coordinate variable is necessary. In addition, taking $\varphi_{1}(t)=\varphi_{2}(t)=h t, h \in(0,1), t \geqslant 0$, we have $\varphi_{1}=\varphi_{2} \in(\Phi)$ and $\varphi(\mathrm{t})=\mathrm{h}^{2} \mathrm{t} \in\left(\Phi_{0}\right)$. Then it is easy to see that $\Psi \subset \mathscr{F}_{\varphi}$. Since $\mathrm{F}_{7} \in \mathscr{F}_{\varphi}$ and $\mathrm{F}_{7} \notin \Psi$, hence $\mathscr{F}_{\varphi} \not \subset \Psi$. These show that the implicit relation of Definition 2.3 is a generalization of Beg and Ahmed [5, implicit relation].

\section{Main results}

In this section, we prove two common fixed point theorems for fuzzy mappings satisfying an implicit $\varphi$-contractive conditions in complete metric spaces, and so also give some corollaries which generalize the results of $[1-8,13,14]$.

Theorem 3.1. Let $(\mathrm{X}, \mathrm{d})$ be a complete metric space and $\mathrm{S}, \mathrm{T}: \mathrm{X} \rightarrow \mathscr{F}(\mathrm{X})$ be two fuzzy mappings satisfying the following conditions:

(a) for each $\mathrm{x} \in \mathrm{X}$, there exists $\alpha(\mathrm{x}) \in(0,1]$ such that $[\mathrm{S} \mathrm{x}]_{\alpha(\mathrm{x})},[\mathrm{T} \mathrm{x}]_{\alpha(\mathrm{x})} \in \mathscr{C}(\mathrm{X})$ and

(b) there exists $\mathrm{F} \in \mathscr{F}_{\varphi}$ such that

$$
F\left(H\left([S x]_{\alpha(x)},[T y]_{\alpha(y)}\right), d(x, y), d\left(x,[S x]_{\alpha(x)}\right), d\left(y,[T y]_{\alpha(y)}\right), d\left(x,[T y]_{\alpha(y)}\right), d\left(y,[S x]_{\alpha(x)}\right)\right) \leqslant 0
$$

for all $x, y \in X$.

Then there exists $z \in \mathrm{X}$ such that $z \in[\mathrm{S} z]_{\alpha(z)} \cap[\mathrm{T} z]_{\alpha(z)}$. 
Proof. Let $x_{0}$ be an arbitrary point in X. For this $x_{0}$, by condition (a), there exists $\alpha\left(x_{0}\right) \in(0,1]$ such that $\left[S x_{0}\right]_{\alpha\left(x_{0}\right)}$ is nonempty compact subset of $X$. For convenience, we denote $\alpha\left(x_{0}\right)$ by $\alpha_{1}$. Choose $x_{1} \in\left[S x_{0}\right]_{\alpha_{1}}$, for this $x_{1}$ there exists $\alpha_{2} \in(0,1]$ such that $\left[T x_{1}\right]_{\alpha_{2}}$ is nonempty compact subset of $X$. Using Lemma 1.2, we know that there exists $x_{2} \in\left[T x_{1}\right]_{\alpha_{2}}$ such that

$$
\mathrm{d}\left(\mathrm{x}_{1}, \mathrm{x}_{2}\right) \leqslant \mathrm{H}\left(\left[S \mathrm{x}_{0}\right]_{\alpha_{1}},\left[\mathrm{~T} \mathrm{x}_{1}\right]_{\alpha_{2}}\right) .
$$

Applying the same argument we can find $\alpha_{3} \in(0,1]$ and $x_{3} \in\left[S x_{2}\right]_{\alpha_{3}}$ such that

$$
\mathrm{d}\left(\mathrm{x}_{2}, \mathrm{x}_{3}\right) \leqslant \mathrm{H}\left(\left[S \mathrm{x}_{2}\right]_{\alpha_{3}},\left[T x_{1}\right]_{\alpha_{2}}\right) .
$$

By induction we produce a sequence $\left\{x_{n}\right\}$ of points of $X$,

$$
x_{2 k+1} \in\left[S x_{2 k}\right]_{\alpha_{2 k+1}}, \quad x_{2 k+2} \in\left[T x_{2 k+1}\right]_{\alpha_{2 k+2}}, \quad k=0,1,2, \cdots,
$$

such that

$$
\mathrm{d}\left(\mathrm{x}_{2 k+1}, \mathrm{x}_{2 \mathrm{k}+2}\right) \leqslant \mathrm{H}\left(\left[\mathrm{S} \mathrm{x}_{2 \mathrm{k}}\right]_{\alpha_{2 k+1}},\left[\mathrm{~T} x_{2 k+1}\right]_{\alpha_{2 k+2}}\right), \mathrm{d}\left(\mathrm{x}_{2 \mathrm{k}+2}, \mathrm{x}_{2 \mathrm{k}+3}\right) \leqslant \mathrm{H}\left(\left[\mathrm{S} x_{2 k+2}\right]_{\alpha_{2 k+3}},\left[\mathrm{~T} x_{2 k+1}\right]_{\alpha_{2 k+2}}\right) .
$$

For $k=0,1,2, \ldots$, applying (3.1) and (3.2), from Lemma 1.1 and the property ( $\mathscr{F}-2)$ of $F$, we have

$$
\begin{aligned}
& F\left(d\left(x_{2 k+1}, x_{2 k+2}\right), d\left(x_{2 k}, x_{2 k+1}\right), d\left(x_{2 k}, x_{2 k+1}\right), d\left(x_{2 k+1}, x_{2 k+2}\right), d\left(x_{2 k}, x_{2 k+1}\right)+d\left(x_{2 k+1}, x_{2 k+2}\right), 0\right) \\
& \quad \leqslant F\left(d\left(x_{2 k+1}, x_{2 k+2}\right), d\left(x_{2 k}, x_{2 k+1}\right), d\left(x_{2 k}, x_{2 k+1}\right), d\left(x_{2 k+1}, x_{2 k+2}\right), d\left(x_{2 k}, x_{2 k+2}\right), d\left(x_{2 k+1}, x_{2 k+1}\right)\right) \\
& \quad \leqslant F\left(H\left(\left[S x_{2 k}\right]_{\alpha_{2 k+1}},\left[T x_{2 k+1}\right]_{\alpha_{2 k+2}}\right), d\left(x_{2 k}, x_{2 k+1}\right), d\left(x_{2 k},\left[S x_{2 k}\right]_{\alpha_{2 k+1}}\right), d\left(x_{2 k+1},\left[T x_{2 k+1}\right]_{\alpha_{2 k+2}}\right),\right. \\
& \left.\quad d\left(x_{2 k},\left[T x_{2 k+1}\right]_{\alpha_{2 k+2}}\right), d\left(x_{2 k+1},\left[S x_{2 k}\right]_{\alpha_{2 k+1}}\right)\right) \leqslant 0,
\end{aligned}
$$

From the property $(\mathscr{F}-3 a)$ of $F$, there exists $\varphi_{1} \in(\Phi)$ such that

$$
d\left(x_{2 k+1}, x_{2 k+2}\right) \leqslant \varphi_{1}\left(d\left(x_{2 k}, x_{2 k+1}\right)\right)
$$

Similarly, applying (3.1) and (3.2), from Lemma 1.1 and the property $(\mathscr{F}-2)$ of $F$, we have

$$
\begin{aligned}
& F\left(d\left(x_{2 k+3}, x_{2 k+2}\right), d\left(x_{2 k+2}, x_{2 k+1}\right), d\left(x_{2 k+2}, x_{2 k+3}\right), d\left(x_{2 k+1}, x_{2 k+2}\right), 0, d\left(x_{2 k+1}, x_{2 k+2}\right)+d\left(x_{2 k+2}, x_{2 k+3}\right)\right) \\
& \quad \leqslant F\left(d\left(x_{2 k+3}, x_{2 k+2}\right), d\left(x_{2 k+2}, x_{2 k+1}\right), d\left(x_{2 k+2}, x_{2 k+3}\right), d\left(x_{2 k+1}, x_{2 k+2}\right), d\left(x_{2 k+2}, x_{2 k+2}\right), d\left(x_{2 k+1}, x_{2 k+3}\right)\right) \\
& \quad \leqslant F\left(H\left(\left[S x_{2 k+2}\right]_{\alpha_{2 k+3}},\left[T x_{2 k+1}\right]_{\alpha_{2 k+2}}\right), d\left(x_{2 k+2}, x_{2 k+1}\right), d\left(x_{2 k+2},\left[S x_{2 k+2}\right]_{\alpha_{2 k+3}}\right),\right. \\
& \left.\quad d\left(x_{2 k+1},\left[T x_{2 k+1}\right]_{\alpha_{2 k+2}}\right), d\left(x_{2 k+2},\left[T x_{2 k+1}\right]_{\alpha_{2 k+2}}\right), d\left(x_{2 k+1},\left[S x_{2 k+2}\right]_{\alpha_{2 k+3}}\right)\right) \leqslant 0 .
\end{aligned}
$$

From the property $(\mathscr{F}-3 b)$ of $F$, there exists $\varphi_{2} \in(\Phi)$ such that

$$
d\left(x_{2 k+2}, x_{2 k+3}\right) \leqslant \varphi_{2}\left(d\left(x_{2 k+1}, x_{2 k+2}\right)\right) .
$$

Since $\varphi_{1}, \varphi_{2} \in(\Phi)$, by the condition (1) of Definition 2.1, (3.3), and (3.4), we can obtain

$$
d\left(x_{2 k+1}, x_{2 k+2}\right) \leqslant \varphi_{1}\left(\varphi_{2}\left(d\left(x_{2 k-1}, x_{2 k}\right)\right)\right) \leqslant \varphi_{1}\left(\varphi\left(d\left(x_{2 k-2}, x_{2 k-1}\right)\right)\right),
$$

and

$$
d\left(x_{2 k+2}, x_{2 k+3}\right) \leqslant \varphi_{2}\left(\varphi_{1}\left(d\left(x_{2 k}, x_{2 k+1}\right)\right)\right)=\varphi\left(d\left(x_{2 k}, x_{2 k+1}\right)\right),
$$

where $\varphi=\varphi_{2} \circ \varphi_{1}$. Using inductive method, for $k=0,1,2, \cdots$, by (3.5) and (3.6), we have

$$
d\left(x_{2 k+1}, x_{2 k+2}\right) \leqslant \varphi_{1}\left(\varphi^{k}\left(d\left(x_{0}, x_{1}\right)\right)\right),
$$

and

$$
d\left(x_{2 k+2}, x_{2 k+3}\right) \leqslant \varphi^{k+1}\left(d\left(x_{0}, x_{1}\right)\right)
$$


Next, we show that the sequence $\left\{x_{n}\right\}$ is a Cauchy sequence in $X$. For any $k<p$, it follows from (3.7) and (3.8) that

$$
\begin{aligned}
d\left(x_{2 k+1}, x_{2 p+1}\right) & \leqslant d\left(x_{2 k+1}, x_{2 k+2}\right)+\cdots+d\left(x_{2 p}, x_{2 p+1}\right) \\
& \leqslant \sum_{i=k}^{p-1} \varphi_{1}\left(\varphi^{i}\left(d\left(x_{0}, x_{1}\right)\right)\right)+\sum_{i=k+1}^{p} \varphi^{i}\left(d\left(x_{0}, x_{1}\right)\right) .
\end{aligned}
$$

Note that $\varphi_{1} \in(\Phi)$, by the condition (1) of Definition 2.1, we know that there exists $M>0$ such that

$$
d\left(x_{2 k+1}, x_{2 p+1}\right) \leqslant M \sum_{i=k}^{p-1} \varphi^{i}\left(d\left(x_{0}, x_{1}\right)\right)+\sum_{i=k+1}^{p} \varphi^{i}\left(d\left(x_{0}, x_{1}\right)\right) \leqslant(M+1) \sum_{i=k}^{\infty} \varphi^{i}\left(d\left(x_{0}, x_{1}\right)\right) .
$$

By the similar reasoning process, we have

$$
\begin{array}{r}
d\left(x_{2 k}, x_{2 p+1}\right) \leqslant(M+1) \sum_{i=k}^{\infty} \varphi^{i}\left(d\left(x_{0}, x_{1}\right)\right), \\
d\left(x_{2 k}, x_{2 p}\right) \leqslant(M+1) \sum_{i=k}^{\infty} \varphi^{i}\left(d\left(x_{0}, x_{1}\right)\right), \\
d\left(x_{2 k+1}, x_{2 p}\right) \leqslant(M+1) \sum_{i=k}^{\infty} \varphi^{i}\left(d\left(x_{0}, x_{1}\right)\right) .
\end{array}
$$

Then there exists $k$ with $\frac{n-1}{2} \leqslant k \leqslant \frac{n}{2}$, for any $0<n<m$, such that

$$
d\left(x_{m}, x_{n}\right) \leqslant(M+1) \sum_{i=k}^{\infty} \varphi^{i}\left(d\left(x_{0}, x_{1}\right)\right) .
$$

Since $\varphi=\varphi_{2} \circ \varphi_{1} \in\left(\Phi_{0}\right)$, i.e., $\sum_{i=1}^{\infty} \varphi^{i}\left(d\left(x_{0}, x_{1}\right)\right)<+\infty$, then $\left\{x_{n}\right\}$ is a Cauchy sequence in $X$. From the completeness of $X$, there exists $z \in X$ such that $x_{n} \rightarrow z$ as $n \rightarrow \infty$.

Now, we claim that $\mathrm{d}\left(z,[\mathrm{~T}(z)]_{\alpha(z)}\right)=0$. If not, then we have $\mathrm{d}\left(z,[\mathrm{~T}(z)]_{\alpha(z)}\right)>0$. Without loss of generality, let us assume that $n$ is even. Using (3.1) and (3.2), from Lemma 1.1 and the property (F्F-2) of $F$, we obtain

$$
\begin{aligned}
& \mathrm{F}\left(\mathrm{d}\left(\mathrm{x}_{2 \mathrm{n}+1},[\mathrm{~T}(z)]_{\alpha(z)}\right), \mathrm{d}\left(x_{2 n}, z\right), \mathrm{d}\left(x_{2 n}, x_{2 n+1}\right), \mathrm{d}\left(z,[\mathrm{~T}(z)]_{\alpha(z)}\right), \mathrm{d}\left(x_{2 n}, z\right)+\mathrm{d}\left(z,[\mathrm{~T}(z)]_{\alpha(z)}\right), \mathrm{d}\left(z, x_{2 n+1}\right)\right) \\
& \quad \leqslant \mathrm{F}\left(\mathrm{H}\left(\left[\mathrm{S} x_{2 n}\right]_{\alpha_{2 n+1}},[\mathrm{~T}(z)]_{\alpha(z)}\right), \mathrm{d}\left(x_{2 n}, z\right), \mathrm{d}\left(x_{2 n},\left[S x_{2 n}\right]_{\alpha_{2 n+1}}\right), \mathrm{d}\left(z,[\mathrm{~T}(z)]_{\alpha(z)}\right),\right. \\
& \left.\quad \mathrm{d}\left(x_{2 n},[\mathrm{~T}(z)]_{\alpha(z)}\right), \mathrm{d}\left(z,\left[S x_{2 n}\right]_{\alpha_{2 n+1}}\right)\right) \leqslant 0 .
\end{aligned}
$$

Note that $\mathrm{d}\left(\mathrm{x}_{2 n}, z\right) \rightarrow 0, \mathrm{~d}\left(\mathrm{x}_{2 n}, \mathrm{x}_{2 n+1}\right) \rightarrow 0$, and $\mathrm{d}\left(\mathrm{x}_{2 n+1},[\mathrm{~T}(z)]_{\alpha(z)}\right) \rightarrow 0$ as $\mathrm{n} \rightarrow \infty$. Let $\mathrm{n} \rightarrow \infty$, by the lower semi-continuity of $F$, we have

$$
\mathrm{F}\left(\mathrm{d}\left(z,[\mathrm{~T}(z)]_{\alpha(z)}\right), 0,0, \mathrm{~d}\left(z,[\mathrm{~T}(z)]_{\alpha(z)}\right), \mathrm{d}\left(z,[\mathrm{~T}(z)]_{\alpha(z)}\right), 0\right) \leqslant 0 .
$$

From (3.9) and the property ( $\mathscr{F}-3 a)$ of F, by Remark 2.2, we can obtain

$$
\mathrm{d}\left(z,[\mathrm{~T}(z)]_{\alpha(z)}\right) \leqslant \varphi_{1}(0)=0,
$$

which is a contradiction. Hence $d\left(z,[T(z)]_{\alpha(z)}\right)=0$, i.e., $z \in[T z]_{\alpha(z)}$.

Similarly, applying (3.1) and (3.2), from Lemma 1.1 and the properties $(\mathscr{F}-2)$ and $(\mathscr{F}-3 b)$ of $F$, it is not difficult to prove that $z \in[S z]_{\alpha(z)}$. Hence $z \in[S z]_{\alpha(z)} \cap\left[T_{z}\right]_{\alpha(z)}$. This completes the proof. 
Theorem 3.2. Let $(\mathrm{X}, \mathrm{d})$ be a complete metric space and $\mathrm{S}, \mathrm{T}: \mathrm{X} \rightarrow \mathscr{W}_{\alpha}(\mathrm{X})$ be two fuzzy mappings on $\mathrm{X}$. Suppose that there exists $\mathrm{F} \in \mathscr{F}_{\varphi}$ such that

$$
\mathrm{F}\left(\mathrm{H}\left([\mathrm{Sx}]_{\alpha},[\mathrm{T} y]_{\alpha}\right), \mathrm{d}(\mathrm{x}, \mathrm{y}), \mathrm{d}\left(\mathrm{x},[\mathrm{Sx}]_{\alpha}\right), \mathrm{d}\left(\mathrm{y},[\mathrm{T} y]_{\alpha}\right), \mathrm{d}\left(\mathrm{x},[\mathrm{T} y]_{\alpha}\right), \mathrm{d}\left(\mathrm{y},[\mathrm{Sx}]_{\alpha}\right)\right) \leqslant 0
$$

for all $x, y \in X$ and $\alpha \in[0,1]$. Then there exists $z \in X$ such that $z_{\alpha} \subset S z$ and $z_{\alpha} \subset T z$.

Proof. Let $x_{0}$ be in $X$. By Lemma 1.4, we know that there exists $x_{1} \in X$ such that $\left\{x_{1}\right\} \subset S x_{0}$, which implies that

$$
\mathrm{d}\left(\mathrm{x}_{1},\left[\mathrm{~S} \mathrm{x}_{0}\right]_{\alpha}\right)=0 \text { for each } \alpha \in[0,1],
$$

which is possible only if $x_{1} \in\left[S x_{0}\right]_{\alpha}$. Since $\left[T x_{1}\right]_{\alpha}$ is a nonempty compact subset of $X$, there exists $x_{2} \in\left[T x_{1}\right]_{\alpha}$ such that

$$
\mathrm{d}\left(\mathrm{x}_{1}, \mathrm{x}_{2}\right) \leqslant \mathrm{H}\left(\left[\mathrm{S} \mathrm{x}_{0}\right]_{\alpha},\left[\mathrm{T} \mathrm{x}_{1}\right]_{\alpha}\right) .
$$

Continuing this process, one obtains a sequence $\left\{x_{n}\right\}$ in $X$ such that

$$
x_{2 k+1} \in\left[S x_{2 k}\right]_{\alpha}, \quad x_{2 k+2} \in\left[T x_{2 k+1}\right]_{\alpha}, k=0,1,2, \cdots,
$$

and

$$
\mathrm{d}\left(\mathrm{x}_{2 k+1}, \mathrm{x}_{2 \mathrm{k}+2}\right) \leqslant \mathrm{H}\left(\left[\mathrm{S} \mathrm{x}_{2 \mathrm{k}}\right]_{\alpha},\left[\mathrm{T} x_{2 k+1}\right]_{\alpha}\right), \mathrm{d}\left(\mathrm{x}_{2 \mathrm{k}+2}, \mathrm{x}_{2 \mathrm{k}+3}\right) \leqslant \mathrm{H}\left(\left[\mathrm{S} \mathrm{x}_{2 \mathrm{k}+2}\right]_{\alpha},\left[\mathrm{T} x_{2 k+1}\right]_{\alpha}\right) .
$$

As in the proof of Theorem 3.1, we can prove that there exists $z \in X$ such that $x_{n} \rightarrow z$ as $n \rightarrow \infty$ and $\mathrm{d}\left(z,[\mathrm{~S}(z)]_{\alpha}\right)=0, \mathrm{~d}\left(z,[\mathrm{~T}(z)]_{\alpha}\right)=0$ for each $\alpha \in[0,1]$. By Lemma 1.3, we know that $z_{\alpha} \subset S z$ and $z_{\alpha} \subset \mathrm{T} z$.

Applying Theorem 3.2, we easily obtain the following fixed point theorems for Chen et al. [6] and Abbas et al. [1,2] type fuzzy mappings. To this end, we need the following definition.

Definition 3.3 (Chen et al. [6, Definition 2.1]). A function $g$ is said to be a G-distance function if $g$ : $[0,+\infty)^{5} \rightarrow[0,+\infty)$ is a continuous function and the following properties hold:

(i) $g$ is nondecreasing in the $2 \mathrm{nd}, 3 \mathrm{rd}, 4$ th, and 5 th variables;

(ii) if $u, v \in[0,+\infty)$ are such that $u \leqslant g(v, v, u, u+v, 0)$ or $u \leqslant g(v, u, v, 0, u+v)$, then $u \leqslant h v$, where $0<\mathrm{h}<1$ is a given constant;

(iii) if $u \in[0,+\infty)$ is such that $u \leqslant g(u, 0,0, u, u)$, then $u=0$.

Definition 3.4 (Chen et al. [6, Definition 3.1]). A function $g$ is said to be a $\mathrm{G}^{\prime}$-distance function if $\mathrm{g}$ : $[0,+\infty)^{5} \rightarrow[0,+\infty)$ is a continuous function and the following properties hold:

(i) $g$ is increasing in each co-ordinate variable;

(ii) $g(t, t, t, a t, b t) \leqslant t$ for every $t \in[0,+\infty)$, where $a+b=2$.

Corollary 3.5 (Chen et al. [6, Theorem 2.1]). Let $(\mathrm{X}, \mathrm{d})$ be a complete metric space and $\mathrm{g}$ be a $\mathrm{G}$-distance function. Suppose that $\mathrm{S}, \mathrm{T}: \mathrm{X} \rightarrow \mathscr{W}_{\alpha}(\mathrm{X})$ are two fuzzy mappings on $\mathrm{X}$ satisfying the following conditions:

$$
\begin{aligned}
\phi\left(H\left([S x]_{\alpha},[T y]_{\alpha}\right)\right) \leqslant & \phi\left(g\left(d(x, y), d\left(x,[S x]_{\alpha}\right), d\left(y,[T y]_{\alpha}\right), d\left(x,[T y]_{\alpha}\right), d\left(y,[S x]_{\alpha}\right)\right)\right) \\
& +\operatorname{Lmin}\left\{d(x, y), d\left(x,[S x]_{\alpha}\right), d\left(y,[T y]_{\alpha}\right), d\left(x,[T y]_{\alpha}\right), d\left(y,[S x]_{\alpha}\right)\right\}
\end{aligned}
$$

for all $x, y \in X$ and $\alpha \in[0,1]$, where $L \geqslant 0$, and $\phi:[0,+\infty) \rightarrow[0,+\infty)$ is a continuous and nondecreasing function with $\phi(\mathrm{t})=0$ if and only if $\mathrm{t}=0$. Then there exists a point $z \in \mathrm{X}$ such that $z_{\alpha} \subset \mathrm{S} z$ and $z_{\alpha} \subset \mathrm{T} z$.

Proof. Let $F\left(t_{1}, t_{2}, t_{3}, t_{4}, t_{5}, t_{6}\right)=\phi\left(t_{1}\right)-\phi\left(g\left(t_{2}, t_{3}, t_{4}, t_{5}, t_{6}\right)\right)-L \min \left\{t_{2}, t_{3}, t_{4}, t_{5}, t_{6}\right\}$. It is evident that $F$ satisfies conditions ( $\mathscr{F}-1)$ and $(\mathscr{F}-2)$ of Definition 2.3.

Now suppose that $F(u, v, v, u, u+v, 0) \leqslant 0$ or $F(u, v, u, v, 0, u+v) \leqslant 0$, i.e., $\phi(u)-\phi(g(v, v, u, u+$ $v, 0)) \leqslant 0$ or $\phi(u)-\phi(g(v, u, v, 0, u+v)) \leqslant 0$. From Definition 3.3, we have

$$
\phi(u) \leqslant \phi(g(v, v, u, u+v, 0)) \Rightarrow u \leqslant g(v, v, u, u+v, 0) \Rightarrow u \leqslant h v
$$

or

$$
\phi(u) \leqslant \phi(g(v, u, v, 0, u+v)) \Rightarrow u \leqslant g(v, u, v, 0, u+v) \Rightarrow u \leqslant h v .
$$

Let $\varphi_{1}(\mathrm{t})=\mathrm{ht}=\varphi_{2}(\mathrm{t})$. Note that $0<\mathrm{h}<1$, we have $\varphi_{1}=\varphi_{2} \in(\Phi), \varphi(\mathrm{t})=\varphi_{2}\left(\varphi_{1}(\mathrm{t})\right)=\mathrm{h}^{2} \mathrm{t} \in\left(\Phi_{0}\right)$. 
These show that $F \in \mathscr{F}_{\varphi}$, which satisfies inequality (3.10) of Theorem 3.2. Then by Theorem 3.2, the corollary is proved.

Remark 3.6. From Remarks 2.1-2.3 and Corollaries 2.5-2.6 in Chen et al. [6], we easily know that Theorems 3.2 and 3.3 in Park and Jeong [13], Theorem 3.2 in Arora and Sharma [4], Theorem 3.1 in Estruch and Vidal [7], and Theorem 3.1 in Heilpern [8] are special cases of Corollary 3.5. Therefore, Corollary 3.5 improves and extends the main results of $[4,6-8,13]$.

Corollary 3.7 (Chen et al. [6, Theorem 3.1]). Let (X, d) be a complete metric space and $\mathrm{g}$ be a $\mathrm{G}^{\prime}$-distance function. Suppose that $\mathrm{S}, \mathrm{T}: \mathrm{X} \rightarrow \mathscr{W}_{\alpha}(\mathrm{X})$ are two fuzzy mappings on $\mathrm{X}$ satisfying the following conditions:

$$
\begin{aligned}
H\left([S x]_{\alpha},[T y]_{\alpha}\right) \leqslant & \psi\left(g\left(d(x, y), d\left(x,[S x]_{\alpha}\right), d\left(y,[T y]_{\alpha}\right), d\left(x,[T y]_{\alpha}\right), d\left(y,[S x]_{\alpha}\right)\right)\right) \\
& +\operatorname{L} \phi\left(\min \left\{d\left(x,[S x]_{\alpha}\right), d\left(y,[T y]_{\alpha}\right), d\left(x,[T y]_{\alpha}\right), d\left(y,[S x]_{\alpha}\right)\right\}\right)
\end{aligned}
$$

for all $x, y \in X$ and $\alpha \in[0,1]$, where $L \geqslant 0, \psi \in\left(\Phi_{0}\right)$, and $\phi:[0,+\infty) \rightarrow[0,+\infty)$ is a lower semi-continuous function with $\phi(\mathrm{t})=0$ if and only if $\mathrm{t}=0$. Then there exists a point $z \in \mathrm{X}$ such that $z_{\alpha} \subset S z$ and $z_{\alpha} \subset \mathrm{T} z$.

Proof. Let $F\left(t_{1}, t_{2}, t_{3}, t_{4}, t_{5}, t_{6}\right)=t_{1}-\psi\left(g\left(t_{2}, t_{3}, t_{4}, t_{5}, t_{6}\right)\right)-L \phi\left(\min \left\{t_{3}, t_{4}, t_{5}, t_{6}\right\}\right)$. It is evident that $F$ satisfies conditions $(\mathscr{F}-1)$ and $(\mathscr{F}-2)$ of Definition 2.3.

Now suppose that $F(u, v, v, u, u+v, 0) \leqslant 0$ or $F(u, v, u, v, 0, u+v) \leqslant 0$, i.e., $u-\psi(g(v, v, u, u+v, 0)) \leqslant 0$ or $u-\psi(g(v, u, v, 0, u+v)) \leqslant 0$. From Definition 3.4, if $u>v \geqslant 0$, then we have $u \leqslant \psi(g(v, v, u, u+v, 0)) \leqslant$ $\psi(g(u, u, u, 2 u, 0 \cdot u)) \leqslant \psi(u)<u$ or $u \leqslant \psi(g(v, u, v, 0, u+v)) \leqslant \psi(g(u, u, u, 0 \cdot u, 2 u) \leqslant \psi(u)<u$, which is a contradiction. Hence $u \leqslant v$, i.e., $u \leqslant \psi(v)$. Let $\varphi_{1}(t)=\psi(t)=\varphi_{2}(t)$. Note that $\psi \in\left(\Phi_{0}\right)$, we have $\varphi_{1}=\varphi_{2} \in(\Phi), \varphi(t)=\varphi_{2}\left(\varphi_{1}(t)\right)=\psi^{2}(t) \in\left(\Phi_{0}\right)$. These show that $\mathrm{F} \in \mathscr{F}_{\varphi}$, which satisfies inequality (3.10) of Theorem 3.2. Then by Theorem 3.2, the corollary is proved.

Remark 3.8. Taking $g\left(t_{2}, t_{3}, t_{4}, t_{5}, t_{6}\right)=\max \left\{t_{2}, t_{3}, t_{4}, \frac{t_{4}+t_{5}}{2}\right\}$ in Corollary 3.7, we can obtain Theorems 3 in Abbas et al. [1]. Taking $g\left(t_{2}, t_{3}, t_{4}, t_{5}, t_{6}\right)=\max \left\{t_{2}, t_{3}, t_{4}, \frac{t_{4}+t_{5}}{2}\right\}$ and $S=T$ in Corollary 3.7, we can obtain Theorems 2.1 in Abbas and Turkoglu [2]. Therefore, Corollary 3.7 improves and extends the main results of $[1,2,6]$.

Corollary 3.9. Let $(X, d)$ be a complete metric space. Suppose that $S, T: X \rightarrow \mathscr{W}_{\alpha}(X)$ are two fuzzy mappings on $X$ satisfying the following conditions:

$$
\begin{aligned}
H^{2}\left([S x]_{\alpha},[T y]_{\alpha}\right) \leqslant & c_{1} \max \left\{d^{2}(x, y), d^{2}\left(x,[S x]_{\alpha}\right), d^{2}\left(y,[T y]_{\alpha}\right)\right\} \\
& +c_{2} \max \left\{d\left(x,[S x]_{\alpha}\right) d\left(x,[T y]_{\alpha}\right), d\left(y,[S x]_{\alpha}\right) d\left(y,[T y]_{\alpha}\right)\right\} \\
& +c_{3} d\left(x,[T y]_{\alpha}\right) d\left(y,[S x]_{\alpha}\right)
\end{aligned}
$$

for all $x, y \in X$ and $\alpha \in[0,1]$, where $c_{1}, c_{2}, c_{3} \geqslant 0$ with $c_{1}+2 c_{2}<1$. Then there exists a point $z \in X$ such that $z_{\alpha} \subset S z$ and $z_{\alpha} \subset \mathrm{T} z$.

Proof. Let $F\left(t_{1}, t_{2}, t_{3}, t_{4}, t_{5}, t_{6}\right)=t_{1}^{2}-c_{1} \max \left\{t_{2}^{2}, t_{3}^{2}, t_{4}^{2}\right\}-c_{2} \max \left\{t_{3} t_{5}, t_{4} t_{6}\right\}-c_{3} t_{5} t_{6}$. It is evident that $F$ satisfies conditions $(\mathscr{F}-1)$ and $(\mathscr{F}-2)$ of Definition 2.3.

Now suppose that $F(u, v, v, u, u+v, 0) \leqslant 0$ or $F(u, v, u, v, 0, u+v) \leqslant 0$, i.e., $u^{2} \leqslant c_{1} \max \left\{v^{2}, u^{2}\right\}+$ $c_{2} v(u+v)$. If $u>v \geqslant 0$, then we have $u^{2} \leqslant\left(c_{1}+2 c_{2}\right) u^{2}<u^{2}$, which is a contradiction. Hence $u \leqslant v$, i.e., $\mathrm{u} \leqslant \sqrt{\mathrm{c}_{1}+2 \mathrm{c}_{2}} v$. Let $\varphi_{1}(\mathrm{t})=\sqrt{\mathrm{c}_{1}+2 \mathrm{c}_{2}} \mathrm{t}=\varphi_{2}(\mathrm{t})$. Note that $\mathrm{c}_{1}+2 \mathrm{c}_{2}<1$, we have $\varphi_{1}=\varphi_{2} \in(\Phi), \varphi(\mathrm{t})=$ $\varphi_{2}\left(\varphi_{1}(t)\right)=\left(c_{1}+2 c_{2}\right) t \in\left(\Phi_{0}\right)$. These show that $F \in \mathscr{F}_{\varphi}$, which satisfies inequality (3.10) of Theorem 3.2. Then by Theorem 3.2, the corollary is proved.

Remark 3.10. Note that $\mathrm{D}(\mathrm{S} x, \mathrm{Ty})=\sup _{\alpha} \mathrm{H}\left([S x]_{\alpha},[\mathrm{Ty}]_{\alpha}\right)$ and $\mathrm{d}(\mathrm{x}, \mathrm{Sx})=\sup _{\alpha} \mathrm{d}\left(\mathrm{x},[S x]_{\alpha}\right)$, from (3.11), we can prove that for all $x, y \in X$,

$$
\begin{aligned}
D^{2}(S x, T y) \leqslant & c_{1} \max \left\{d^{2}(x, y), d^{2}(x, S x), d^{2}(y, T y)\right\}+c_{2} \max \{d(x, S x) d(x, T y), d(y, S x) d(y, T y)\} \\
& +c_{3} d(x, T y) d(y, S x) .
\end{aligned}
$$


Then the conclusion of Corollary 3.9 remains valid. Moreover, this result generalizes Theorem 3.3 in Ahmed [3]. Our result shows that the condition $c_{2}+c_{3}<1$ in Theorem 3.3 in Ahmed [3] is unnecessary. Further, by Remark 3.2 (II) in Ahmed [3], we can see that Corollary 3.9 also generalizes Theorem 3.3 of Park and Jeong [13].

Corollary 3.11. Let $(\mathrm{X}, \mathrm{d})$ be a complete metric space. Suppose that $\mathrm{S}, \mathrm{T}: \mathrm{X} \rightarrow \mathscr{W}_{\alpha}(\mathrm{X})$ are two fuzzy mappings on $\mathrm{X}$ satisfying the following conditions:

$$
\begin{aligned}
H^{2}\left([S x]_{\alpha},[T y]_{\alpha}\right) \leqslant & a_{1} d^{2}(x, y)+a_{2} d\left(x,[S x]_{\alpha}\right) d\left(y,[T y]_{\alpha}\right)+a_{3} d\left(x,[T y]_{\alpha}\right) d\left(y,[S x]_{\alpha}\right) \\
& +a_{4} d(x, y) d\left(x,[S x]_{\alpha}\right)+a_{5} d(x, y) d\left(y,[T y]_{\alpha}\right)
\end{aligned}
$$

for all $x, y \in X$ and $\alpha \in[0,1]$, where $a_{1}, a_{2}, a_{3}, a_{4}, a_{5} \geqslant 0$ and $a_{1}+a_{2}+a_{4}+a_{5}<1$. Then there exists a point $z \in \mathrm{X}$ such that $z_{\alpha} \subset \mathrm{Sz}$ and $z_{\alpha} \subset \mathrm{T} z$.

Proof. We can consider the function $F\left(t_{1}, t_{2}, t_{3}, t_{4}, t_{5}, t_{6}\right)=t_{1}^{2}-a_{1} t_{2}^{2}-a_{2} t_{3} t_{4}-a_{3} t_{5} t_{6}-a_{4} t_{2} t_{3}-a_{5} t_{2} t_{4}$. It is evident that $\mathrm{F}$ satisfies conditions $(\mathscr{F}-1)$ and $(\mathscr{F}-2)$ of Definition 2.3.

Now suppose that $F(u, v, v, u, u+v, 0) \leqslant 0$ or $F(u, v, u, v, 0, u+v) \leqslant 0$, i.e., $u^{2}-a_{1} v^{2}-a_{2} v u-a_{4} v^{2}-$ $a_{5} u v \leqslant 0$ or $u^{2}-a_{1} v^{2}-a_{2} u v-a_{4} v u-a_{5} v^{2} \leqslant 0$. If $u>v \geqslant 0$, then we have $u^{2} \leqslant\left(a_{1}+a_{2}+a_{4}+\right.$ $\left.a_{5}\right) u^{2}<u^{2}$, which is a contradiction. Hence $u \leqslant v$, i.e., $u \leqslant \sqrt{a_{1}+a_{2}+a_{4}+a_{5}} v$. Let $\varphi_{1}(t)=$ $\sqrt{a_{1}+a_{2}+a_{4}+a_{5}} t=\varphi_{2}(t)$. Note that $\sqrt{a_{1}+a_{2}+a_{4}+a_{5}}<1$, we have $\varphi_{1}=\varphi_{2} \in(\Phi), \varphi(t)=$ $\varphi_{2}\left(\varphi_{1}(t)\right) \in\left(\Phi_{0}\right)$. These show that $F \in \mathscr{F}_{\varphi}$, which satisfies inequality (3.10) of Theorem 3.2. Then by Theorem 3.2, the corollary is proved.

Remark 3.12. Our result shows that the condition $a_{1}+a_{3}<1$ in Theorem 4.1 in Chen et al. [6] is unnecessary, which implies that Corollary 3.11 generalizes Theorem 4.1 of Chen et al. [6].

Note that $\Psi \subset \mathscr{F}_{\varphi}$, in Theorem 3.2, taking $F \in \Psi$, we obtain the following corollary.

Corollary 3.13. Let $(\mathrm{X}, \mathrm{d})$ be a complete metric space and $\mathrm{S}, \mathrm{T}: \mathrm{X} \rightarrow \mathscr{W}_{\alpha}(\mathrm{X})$ be two fuzzy mappings on $\mathrm{X}$. Suppose that there exists $\mathrm{F} \in \mathscr{F}_{\varphi}$ such that

$$
F\left(H\left([S x]_{\alpha},[T y]_{\alpha}\right), d(x, y), d\left(x,[S x]_{\alpha}\right), d\left(y,[T y]_{\alpha}\right), d\left(x,[T y]_{\alpha}\right), d\left(y,[S x]_{\alpha}\right)\right) \leqslant 0
$$

for all $x, y \in X$ and $\alpha \in[0,1]$. Then there exists $z \in X$ such that $z_{\alpha} \subset S z$ and $z_{\alpha} \subset \mathrm{T} z$.

Remark 3.14. This result generalizes Theorem 2.6 in Beg and Ahmed [5]. Moreover, by Remark 2.8 in Beg and Ahmed [5], we can see that Corollary 3.13 also generalizes Theorem 2.1 of Rashwan and Ahmed [14].

\section{Applications and examples}

In this section, we first establish a common fixed point theorem for multi-valued mappings satisfying an implicit $\varphi$-contractive conditions in complete metric spaces. After that, we give two examples to discuss the validity of the hypotheses of Theorem 3.1, by which we can claim that our results improve and extend several known results in the existing literature.

Theorem 4.1. Let $(\mathrm{X}, \mathrm{d})$ be a complete metric space and $\mathrm{S}, \mathrm{T}: \mathrm{X} \rightarrow \mathscr{C}(\mathrm{X})$ be two multi-valued mappings. Suppose that there exists $\mathrm{F} \in \mathscr{F}_{\varphi}$ such that for all $x, y \in X$

$$
F(H(S x, T y), d(x, y), d(x, S x), d(y, T y), d(x, T y), d(y, S x)) \leqslant 0 .
$$

Then there exists $z \in X$ such that $z \in S z \cap T z$.

Proof. Let the fuzzy mappings $S, T: X \rightarrow \mathscr{F}(X)$ be defined as $S(x)=\chi_{S(x)}$ and $T(x)=\chi_{T(x)}$, where $\chi_{A}$ is the characteristic function on any subset $A$ of $X$. Using the facts $[S x]_{\alpha(x)}=S(x),[T x]_{\alpha(x)}=T(x)$ for any $\alpha(x) \in[0,1]$, it is evident that $S$ and T satisfy the conditions of Theorem 3.1. Then, by Theorem 3.1, the theorem is proved. 
Corollary 4.2 (Iseki [9]). Let (X, d) be a complete metric space and $\mathrm{S}, \mathrm{T}: \mathrm{X} \rightarrow \mathscr{C}(\mathrm{X})$ be two multi-valued mappings. Suppose that for all $x, y \in X$

$$
H(S x, T y) \leqslant a d(x, y)+b[d(x, S x)+d(y, T y)]+c[d(x, T y)+d(y, S x)],
$$

where $a, b, c \geqslant 0$ with $a+2 b+2 c<1$. Then there exists $z \in X$ such that $z \in S z \cap T z$.

Proof. We consider the function $\mathrm{F}: \mathbb{R}_{6}^{+} \rightarrow \mathbb{R}$ defined by

$$
F\left(t_{1}, t_{2}, t_{3}, t_{4}, t_{5}, t_{6}\right)=t_{1}-a t_{2}-b\left(t_{3}+t_{4}\right)-c\left(t_{5}+t_{6}\right) .
$$

Since $\mathrm{F} \in \mathscr{F}_{\varphi}$ we can apply Theorem 4.1 and obtain Corollary 4.2.

Corollary 4.3 (Singh and Whitfield [16]). Let $(\mathrm{X}, \mathrm{d})$ be a complete metric space and $\mathrm{S}, \mathrm{T}: \mathrm{X} \rightarrow \mathscr{C}(\mathrm{X})$ be two multi-valued mappings. Suppose that for all $x, y \in X$

$$
H(S x, T y) \leqslant \operatorname{amax}\left\{d(x, y), \frac{1}{2}[d(x, S x)+d(y, T y)], \frac{1}{2}[d(x, T y)+d(y, S x)]\right\},
$$

where $\mathrm{a} \in[0,1)$. Then there exists $z \in \mathrm{X}$ such that $z \in \mathrm{S} z \cap \mathrm{T} z$.

Proof. We consider the function $\mathrm{F}: \mathbb{R}_{6}^{+} \rightarrow \mathbb{R}$ defined by

$$
F\left(t_{1}, t_{2}, t_{3}, t_{4}, t_{5}, t_{6}\right)=t_{1}-a \max \left\{t_{2}, \frac{1}{2}\left(t_{3}+t_{4}\right), \frac{1}{2}\left(t_{5}+t_{6}\right)\right\} .
$$

Since $\mathrm{F} \in \mathscr{F}_{\varphi}$, we can apply Theorem 4.1 and obtain Corollary 4.3 .

Example 4.4. Let $X=[0,2]$ endowed with the metric d defined by $d(x, y)=|x-y|$. It is clear that $(X, d)$ is a complete metric space. Assume that $F\left(t_{1}, t_{2}, t_{3}, t_{4}, t_{5}, t_{6}\right)=t_{1}-\frac{1}{2} t_{2}-\frac{3}{8} t_{6}$ for all $t_{1}, t_{2}, t_{3}, t_{4}, t_{5}, t_{6} \in \mathbb{R}^{+}$. It is obvious that $F \in \mathscr{F}_{\varphi}$, where $\varphi_{1}(\mathrm{t})=\frac{1}{2} \mathrm{t}, \varphi_{2}(\mathrm{t})=\frac{7}{5} \mathrm{t}$ and $\varphi(\mathrm{t})=\frac{7}{10} \mathrm{t}$. Let $\mathrm{S}=\mathrm{T}$. Define a fuzzy mapping $S$ on $X$ such that

$$
(S x)(z)=\left\{\begin{array}{ll}
1, & z=0, \\
0, & z \neq 0,
\end{array} \text { for all } x \in[0,1]\right.
$$

and

$$
(\mathrm{S} x)(z)=\left\{\begin{array}{ll}
1, & z=1 / 8, \\
0, & z \neq 1 / 8,
\end{array} \text { for all } x \in(1,2]\right.
$$

Then we have

$$
[S x]_{1}=[S x]_{\alpha}=\{0\} \text { for all } x \in[0,1] \text { and } \alpha \in(0,1]
$$

and

$$
[\mathrm{S} x]_{1}=[\mathrm{S} x]_{\alpha}=\left\{\frac{1}{8}\right\} \text { for all } x \in(1,2] \text { and } \alpha \in(0,1] .
$$

For $x, y \in X$, we only need to consider the following two cases.

Case 1. If $x \in[0,1]$ and $y \in(1,2]$, then for all $\alpha \in(0,1]$ we have

$$
\frac{1}{8}-\frac{1}{2}|x-y|-\frac{3}{8}|y-0| \leqslant 0,
$$

which implies that (3.1) holds.

Case 2. If $x \in(1,2]$ and $y \in[0,1]$, then for all $\alpha \in(0,1]$ we have

$$
\frac{1}{8}-\frac{1}{2}|x-y|-\frac{3}{8}\left|y-\frac{1}{8}\right| \leqslant \begin{cases}\frac{1}{8}-\frac{3}{8}\left|\frac{11}{24}-\frac{1}{8}\right|=0, & y \in\left[\frac{11}{24}, 1\right], \\ \frac{1}{8}-\frac{1}{2}\left|1-\frac{11}{24}\right|<0, & y \in\left[0, \frac{11}{24}\right),\end{cases}
$$

which implies that (3.1) also holds. 
Thus, the conditions of Theorem 3.1 are satisfied, and there exists $0 \in X$ such that $0 \in[\mathrm{S} 0]_{\alpha}$ for all $\alpha \in(0,1]$. This shows the validity of the hypotheses of our main results.

Example 4.5. Let $X=[0,+\infty)$ and $d$ be a discrete metric, then $(X, d)$ is a complete metric space. Assume that $F\left(t_{1}, t_{2}, t_{3}, t_{4}, t_{5}, t_{6}\right)=t_{1}-\frac{1}{40} t_{2}-\frac{1}{40} t_{3}-\frac{19}{40} t_{4}-\frac{1}{40} t_{5}-\frac{1}{2} t_{6}$ for all $t_{1}, t_{2}, t_{3}, t_{4}, t_{5}, t_{6} \in \mathbb{R}^{+}$. By Example 2.9 , we can see that $F \in \mathscr{F}_{\varphi}$, where $\varphi_{1}(\mathrm{t})=\frac{3}{20} \mathrm{t}, \varphi_{2}(\mathrm{t})=\frac{40}{19} \mathrm{t} \in(\Phi)$ and $\varphi(t)=\frac{6}{19} \in\left(\Phi_{0}\right)$. Define two fuzzy mappings $\mathrm{S}, \mathrm{T}: \mathrm{X} \rightarrow \mathscr{W}_{\alpha}(\mathrm{X})$ as follows:

$$
\begin{aligned}
& (\mathrm{S} x)(z)=\left\{\begin{array}{ll}
1, & z=0, \\
0, & z \neq 0,
\end{array} \quad \text { for all } x \in[0,+\infty),\right. \\
& (\mathrm{T} 3)(z)=\left\{\begin{array}{ll}
1, & z=1, \\
0, & z \neq 1,
\end{array} \quad(\mathrm{~T} x)(z)=\left\{\begin{array}{ll}
1, & z=0, \\
0, & z \neq 0,
\end{array} \text { for all } x \in[0,+\infty) \backslash\{3\} .\right.\right.
\end{aligned}
$$

Then we have

$$
[S x]_{1}=[S x]_{\alpha}=\{0\} \text { for all } x \in[0,1] \text { and } \alpha \in[0,+\infty)
$$

and

$$
[\mathrm{Ty}]_{1}=[\mathrm{T} y]_{\alpha}=\left\{\begin{array}{ll}
\{1\}, & y=3, \\
\{0\}, & y \neq 3,
\end{array} \text { for all } \alpha \in(0,1]\right.
$$

For $x, y \in X$, we need to consider the following five cases.

Case 1. If $x \in[0,+\infty)$ and $y \in[0,+\infty) \backslash\{3\}$, then for all $\alpha \in(0,1]$ we have

$$
\mathrm{H}(\{0\},\{0\})-\frac{1}{40} \mathrm{~d}(x, y)-\frac{1}{40} \mathrm{~d}(x,\{0\})-\frac{19}{40} \mathrm{~d}(\mathrm{y},\{0\})-\frac{1}{40} \mathrm{~d}(x,\{0\})-\frac{1}{2} \mathrm{~d}(\mathrm{y},\{0\}) \leqslant 0,
$$

which implies that (3.1) holds.

Case 2. If $x=0$ and $y=3$, then for all $\alpha \in(0,1]$ we have

$$
H(\{0\},\{1\})-\frac{1}{40} d(0,3)-\frac{1}{40} d(0,\{0\})-\frac{19}{40} d(3,\{1\})-\frac{1}{40} d(0,\{1\})-\frac{1}{2} d(3,\{0\})=-\frac{1}{40} \leqslant 0,
$$

which implies that (3.1) also holds.

Case 3. If $x=1$ and $y=3$, then for all $\alpha \in(0,1]$ we have

$$
\mathrm{H}(\{0\},\{1\})-\frac{1}{40} \mathrm{~d}(1,3)-\frac{1}{40} \mathrm{~d}(1,\{0\})-\frac{19}{40} \mathrm{~d}(3,\{1\})-\frac{1}{40} \mathrm{~d}(1,\{1\})-\frac{1}{2} \mathrm{~d}(3,\{0\})=-\frac{1}{40} \leqslant 0 .
$$

Case 4. If $x=3$ and $y=3$, then for all $\alpha \in(0,1]$ we have

$$
\mathrm{H}(\{0\},\{1\})-\frac{1}{40} \mathrm{~d}(3,3)-\frac{1}{40} \mathrm{~d}(3,\{0\})-\frac{19}{40} \mathrm{~d}(3,\{1\})-\frac{1}{40} \mathrm{~d}(3,\{1\})-\frac{1}{2} \mathrm{~d}(3,\{0\})=-\frac{1}{40} \leqslant 0 .
$$

Case 5. If $x=[0,+\infty) \backslash\{0,1,3\}$ and $y=3$, then for all $\alpha \in(0,1]$ we have

$$
H(\{0\},\{1\})-\frac{1}{40} d(x, 3)-\frac{1}{40} d(x,\{0\})-\frac{19}{40} d(3,\{1\})-\frac{1}{40} d(x,\{1\})-\frac{1}{2} d(3,\{0\})=-\frac{1}{20} \leqslant 0 .
$$

Thus, the conditions of Theorem 3.1 are satisfied, and there exists $0 \in \mathrm{X}$ such that $0 \in\{0\}=[\mathrm{S} 0]_{\alpha} \cap[\mathrm{T} 0]_{\alpha}$ for all $\alpha \in(0,1]$. But for any $a_{i} \geqslant 0(i=1,2, \cdots, 5)$ with $\sum_{i=1}^{5} a_{i}<1$, we have

$$
\begin{aligned}
H\left([S 3]_{\alpha},[T 3]_{\alpha}\right)=H(\{0\},\{1\})=1 & >a_{1}+a_{2}+a_{3}+a_{4}+a_{5} \\
& >a_{1} d(3,3)+a_{2} \frac{1}{40} d(3,\{0\})+a_{3} d(3,\{1\})+a_{4} d(3,\{1\})+a_{5} d(3,\{0\})
\end{aligned}
$$

for all $\alpha \in(0,1]$. Thus $S, T$ cannot satisfy the general contractive condition $\sum_{i=1}^{5} a_{i}<1$. This shows that our results improve and extend several known results in the existing literature. 


\section{Acknowledgment}

This work was supported by the Natural Science Foundation of the Jiangsu Higher Education Institutions (Grant no. 15KJB110003, 16KJD110001).

\section{References}

[1] M. Abbas, B. Damjanović, R. Lazović, Fuzzy common fixed point theorems for generalized contractive mappings, Appl. Math. Lett., 23 (2010), 1326-1330. 1, 3, 3, 3.8

[2] M. Abbas, D. Turkoglu, Fixed point theorem for a generalized contractive fuzzy mapping, J. Intell. Fuzzy Systems, 26 (2014), 33-36. 3, 3.8

[3] M. A. Ahmed, Fixed point theorems in fuzzy metric spaces, J. Egyptian Math. Soc., 22 (2014), 59-62. 3.10

[4] S. C. Arora, V. Sharma, Fixed point theorems for fuzzy mappings, Fuzzy Sets and Systems, 110 (2000), 127-130. 3.6

[5] I. Beg, M. A. Ahmed, Fixed point for fuzzy contraction mappings satisfying an implicit relation, Mat. Vesnik, 66 (2014), 351-356. 1, 2.13, 2.14, 3.14

[6] J.-H. Chen, X.-J. Huang, Fixed point theorems for fuzzy mappings in metric spaces with an application, J. Inequal. Appl., 2015 (2015), 21 pages. 1, 3, 3.3, 3.4, 3.5, 3.6, 3.7, 3.8, 3.12

[7] V. D. Estruch, A. Vidal, A note on fixed fuzzy points for fuzzy mappings, Proceedings of the "II Italian-Spanish Congress on General Topology and its Applications" (Italian), Trieste, (1999), Rend. Istit. Mat. Univ. Trieste, 32 (2001), 39-45. 1, 3.6

[8] S. Heilpern, Fuzzy mappings and fixed point theorem, J. Math. Anal. Appl., 83 (1981), 566-569. 1, 1.3, 3, 3.6

[9] K. Iseki, Multi-valued contraction mappings in complete metric spaces, Rend. Sem. Mat. Univ. Padova, 53 (1975), 15-19. 4.2

[10] B. S. Lee, S. J. Cho, A fixed point theorem for contractive-type fuzzy mappings, Fuzzy Sets and Systems, 61 (1994), 309-312. 1, 1.4

[11] S. B. Nadler, Jr., Multi-valued contraction mappings, Pacific J. Math., 30 (1968), 369-380. 1, 1.1, 1.2

[12] J. Y. Park, J. U. Jeong, Common fixed points of fuzzy mappings, Fuzzy Sets and Systems, 59 (1993), 231-235. 1

[13] J. Y. Park, J. U. Jeong, Fixed point theorems for fuzzy mappings, Fuzzy Sets and Systems, 87 (1997), 111-116. 1, 3, 3.6, 3.10

[14] R. A. Rashwan, M. A. Ahmed, Common fixed point theorems for fuzzy mappings, Arch. Math. (Brno), 38 (2002), 219-226. 1, 3, 3.14

[15] S. Sedghi, N. Shobe, I. Altun, A fixed fuzzy point for fuzzy mappings in complete metric spaces, Math. Commun., 13 (2008), 289-294. 1

[16] K. L. Singh, J. H. M. Whitfield, Fixed points for contractive type multivalued mappings, Math. Japon., 27 (1982), 117-124. 4.3

[17] T. Som, R. N. Mukherjee, Some fixed point theorems for fuzzy mappings, Fuzzy Sets and Systems, 33 (1989), $213-219$. 1

[18] M.-L. Song, X.-J. Zhang, Common fixed point theorems for Lipschitz-type fuzzy mappings in metric spaces, Fixed point Theory Appl., 2013 (2013), 14 pages. 1 